\title{
Large-Volume Battery Calorimeter
}

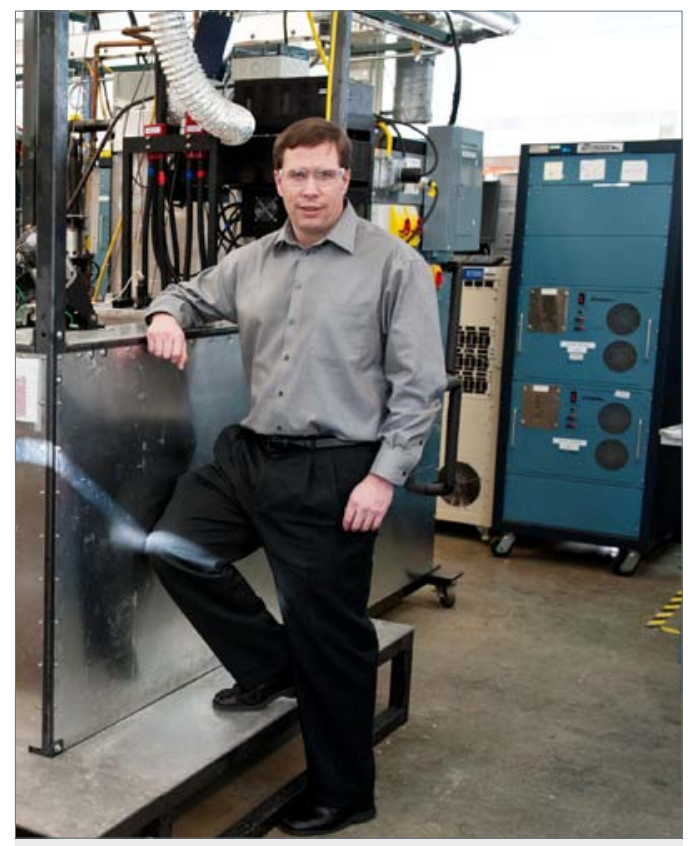

Senior Engineer Matthew Keyser with the Large Volume Battery Calorimeter connected to a battery tester in the back. Photo by Dennis Schroeder, NREL/PIX 18906

As more electric-drive vehicles

continue to enter the market,

NREL's Large-Volume Battery

Calorimeter provides the scale

and accuracy to optimize thermal

management and battery life.

\section{Providing Thermal Characterization for the Next Generation of Batteries for Electric-Drive Vehicles}

\section{Larger Batteries Deliver Greater Energy, Power and Testing Challenges}

Rising fuel efficiency standards and consumer demand for environmentallyfriendly automobiles have manufacturers racing to put more hybrids (HEVs), plug-in hybrids (PHEVs) and electric vehicles (EVs) on the road. To make these options practical, automotive batteries need to operate at maximum efficiency, performing at optimal temperatures in a wide range of driving conditions and climates, and through numerous charging cycles.

Demands for driving ranges and power comparable to that of gasolinefueled vehicles call for electric-drive vehicle battery packs to be larger than traditional car batteries, requiring industry and research organizations to accurately analyze thermal performance and heat generation. Correct thermal management improves battery life, efficiency, reliability, performance and safety. As drivers continue to demand ever-more-green but affordable car models, NREL, with support from the Department of Energy (DOE), is using the Large-Volume Battery Calorimeter (LVBC) to help industry design better thermal management systems for energy storage cells, modules and packs for these electric-drive vehicles.

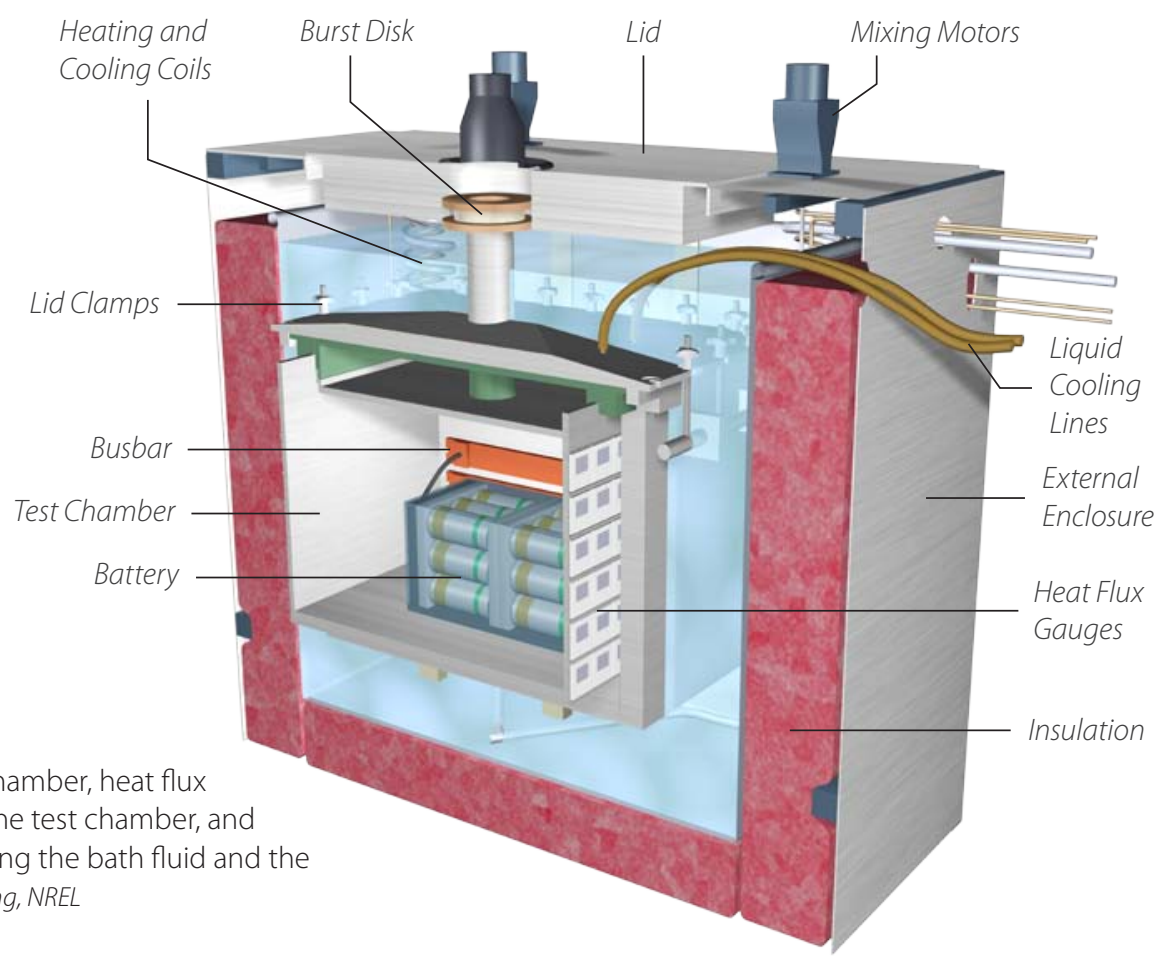

Cutaway showing battery in the test chamber, heat flux gauges, isothermal fluid surrounding the test chamber, and outside container with insulation holding the bath fluid and the test chamber. Illustration by Dean Armstrong, NREL 


\section{NREL's Large-Volume Battery Calorimeter is designed to:}

- Obtain accurate heat generation data for modules developed by battery manufacturers under different modes of system operation, battery power profiles and operating temperatures.

- Measure round-trip energy efficiency (i.e., to distinguish energy stored from waste heat generated) for use in estimating vehicle energy consumption.

- Compile data to validate and refine thermal models developed by researchers, battery developers and vehicle manufacturers.

- Generate a performance history to evaluate the effects of aging and cycling.

- Evaluate physical and electrochemical design changes that could lead to better battery modules and improved performance.

Battery in the test chamber of the LVBC (left). In the graph (right), the red curve shows electrical power input to the battery, and the green curve shows the heat signature measured. Illustration by Dean Armstrong, NREL
- Understand the heat lost due to inefficient interconnects within a module or pack, as well as those from the energy storage cells.

- Evaluate the efficacy of liquid-cooled energy storage systems.

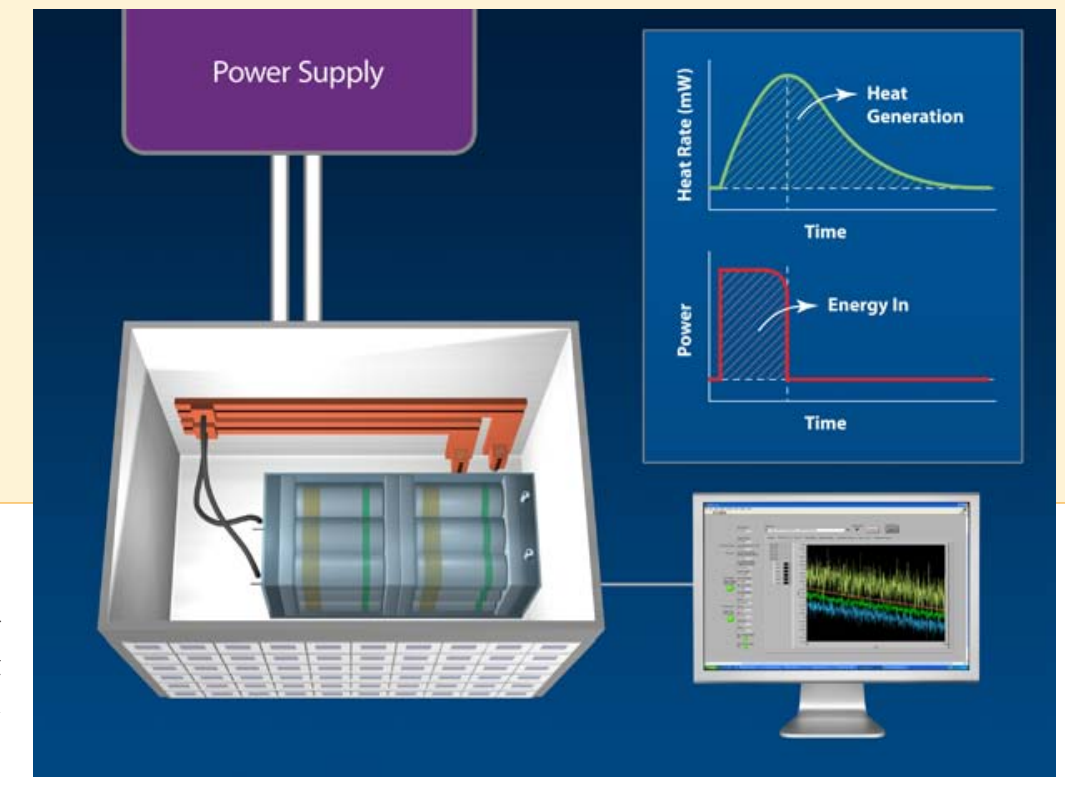

\section{What Makes Battery Temperature Important?}

A well-designed thermal management system is critical to the life and performance of HEV, PHEV and electric vehicles. Regulation of battery pack temperature helps maximize performance (power and capacity) and charge acceptance (during regenerative braking), while minimizing battery degradation, and vehicle operating and maintenance expenses.

As electrochemical devices, batteries' performance and lifespan are affected by temperature. High temperatures increase side reactions, shortening battery life and increasing battery replacement costs.

Development of precisely-calibrated battery systems relies on accurate measurements of heat generated by battery modules during the full range of charge/discharge cycles, as well as determination of whether the heat was generated electrochemically or resistively. DOE and car and battery industry experts identified an unmet need for an accurate large battery calorimeter with capability of testing liquid-cooled systems, therefore DOE provided funding for NREL to design and build a calorimeter for large battery packs with the option of liquid cooling.

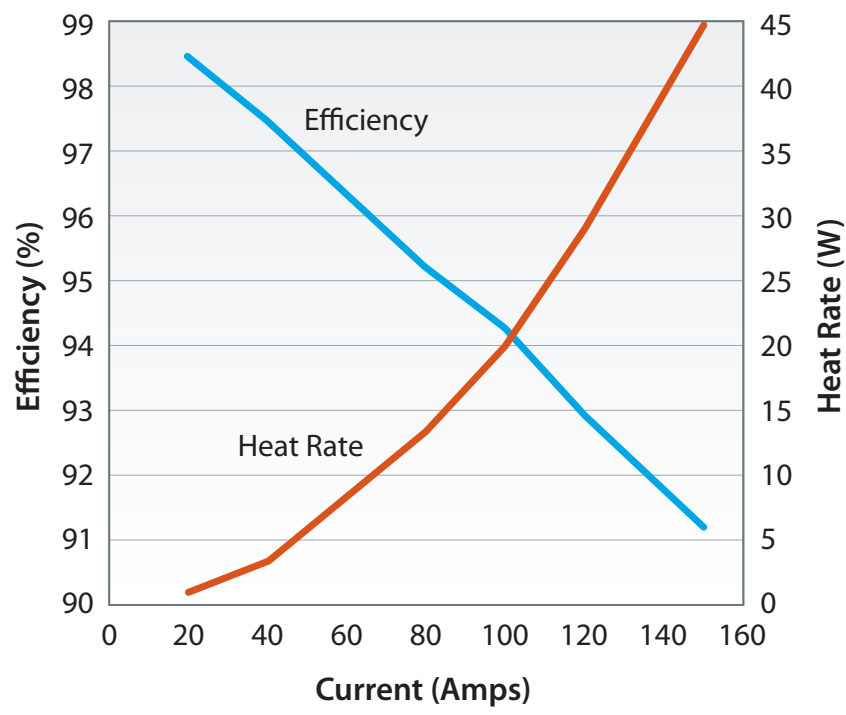

Results of constant current testing of a lithium ion battery in the NREL calorimeter. Heat rate loss (red line) and thermal efficiency (blue line). Source: Matt Keyser, NREL. Graph by Dean Armstrong, NREL 


\section{Fine-Tuning Designs with a One-of-a-Kind Calorimeter}

The United States Advanced Battery Consortium (USABC) and its partners-including Johnson Controls Inc., Saft, A123 Systems, Compact Power Incorporated, EnerDel and other companies-ship products to NREL to precisely measure their heat generation and efficiency under different states of charge, power profiles and temperatures. The LVBC, with a volume of 96 liters, is the first calorimeter designed to analyze heat loads generated by complete battery systems. It can measure heat generation rates as low as 15 milliWatts and up to 4,000 Watts, with overall heat-load-measuring accuracy from a battery to within $\pm 2 \%$.

These LVBC capabilities make it possible for battery developers to predict thermal performance before installing batteries in vehicles. Manufacturers can use these metrics to compare battery performance to industry averages, troubleshoot thermal issues and fine-tune design.
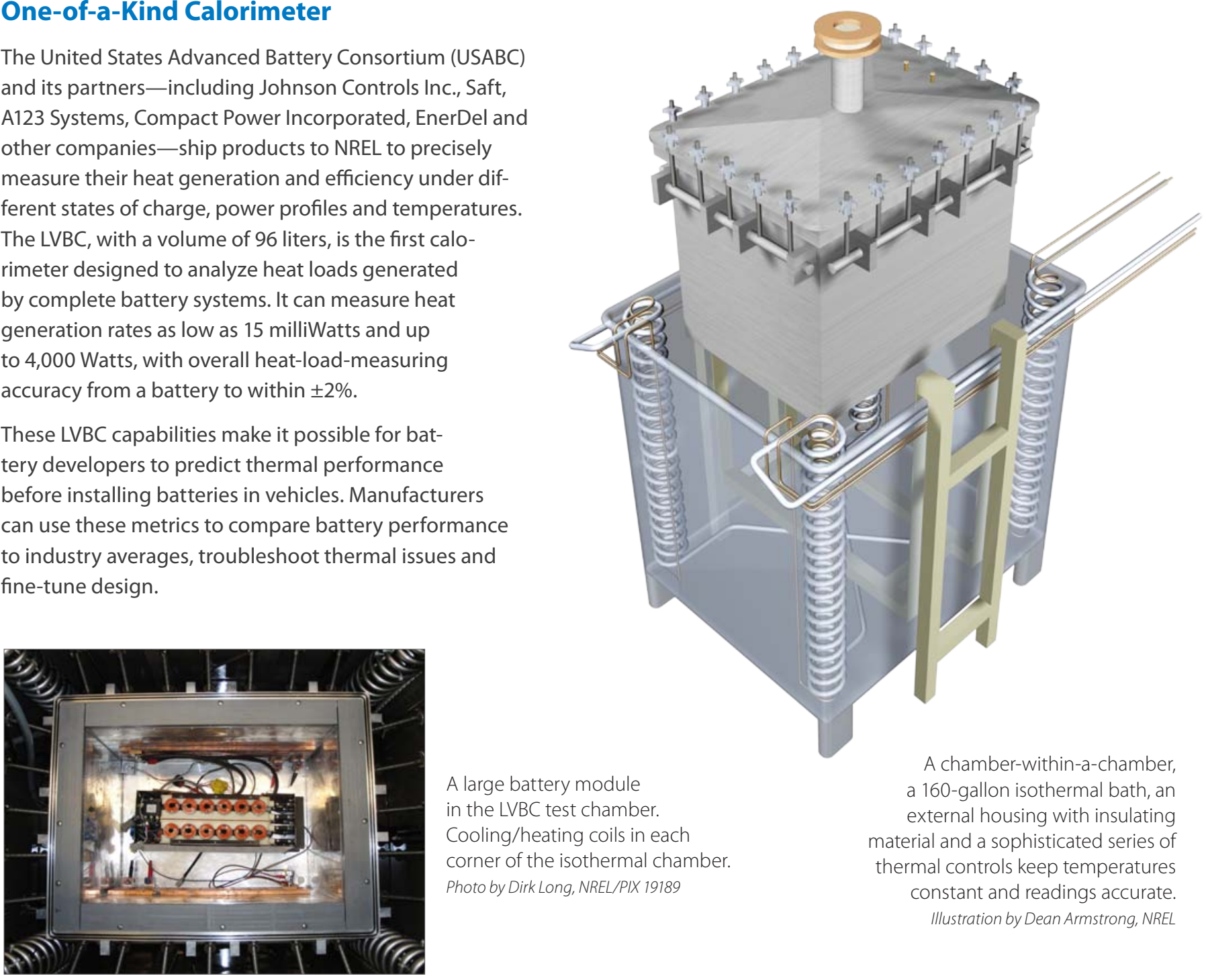

A large battery module in the LVBC test chamber. Cooling/heating coils in each corner of the isothermal chamber. Photo by Dirk Long, NREL/PIX 19189
A chamber-within-a-chamber a 160-gallon isothermal bath, an external housing with insulating material and a sophisticated series of thermal controls keep temperatures constant and readings accurate. Illustration by Dean Armstrong, NREL

\section{Large-Volume Battery Calorimeter Specifications}

Maximum Voltage (Volts) ..............................60 600

Sustained Maximum Current (Amps) ..................... 500

Excursion Currents (Amps) ............................ 1000

Maximum Battery Weight for Testing $(\mathrm{kg}) \ldots \ldots \ldots \ldots \ldots \ldots \ldots . \ldots 200$

Test Cavity Volume (liters) $\ldots \ldots \ldots \ldots \ldots \ldots \ldots \ldots \ldots \ldots \ldots$

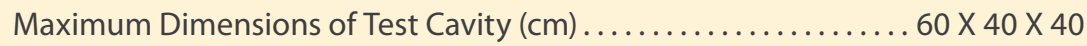

Operating Temperature $\left({ }^{\circ} \mathrm{C}\right) \ldots \ldots \ldots \ldots \ldots \ldots \ldots \ldots \ldots \ldots \ldots \ldots \ldots \ldots \ldots$ to +100

Maximum Constant Heat Generation (Watts)............... 4,000

Minimum Detectable Heat Effect (Joules) .................. 15

Baseline Stability (milliWatts) ........................ 5-10 


\section{Highlights}

- Accuracy of 98 percent in measuring heat

- Ability to test cells from 0.5 Ah to $100 \mathrm{Ah}$

- Ability to measure battery packs with energy content of $2 \mathrm{Wh}$ to $10 \mathrm{kWh}$

- Assessment of heat from entire battery systems, including interconnects

- Innovative thermal isolation and isothermal bath providing errors of less than $\pm 2 \%$

- Simulation of full range of driving conditions and charging cycles

- Ability to test liquid-cooled batteries

Top: An external heating and cooling system (on right) keeps the isothermal bath of the calorimeter (on left) at a uniform and constant temperature. Photo by Ahmad Pesaran, NREL/PIX 19190

Right: The lid of the test chamber is sealed with 24 clamps before the chamber is immersed in the isothermal bath. Photo by Dennis Schroeder, NREL/PIX 18907
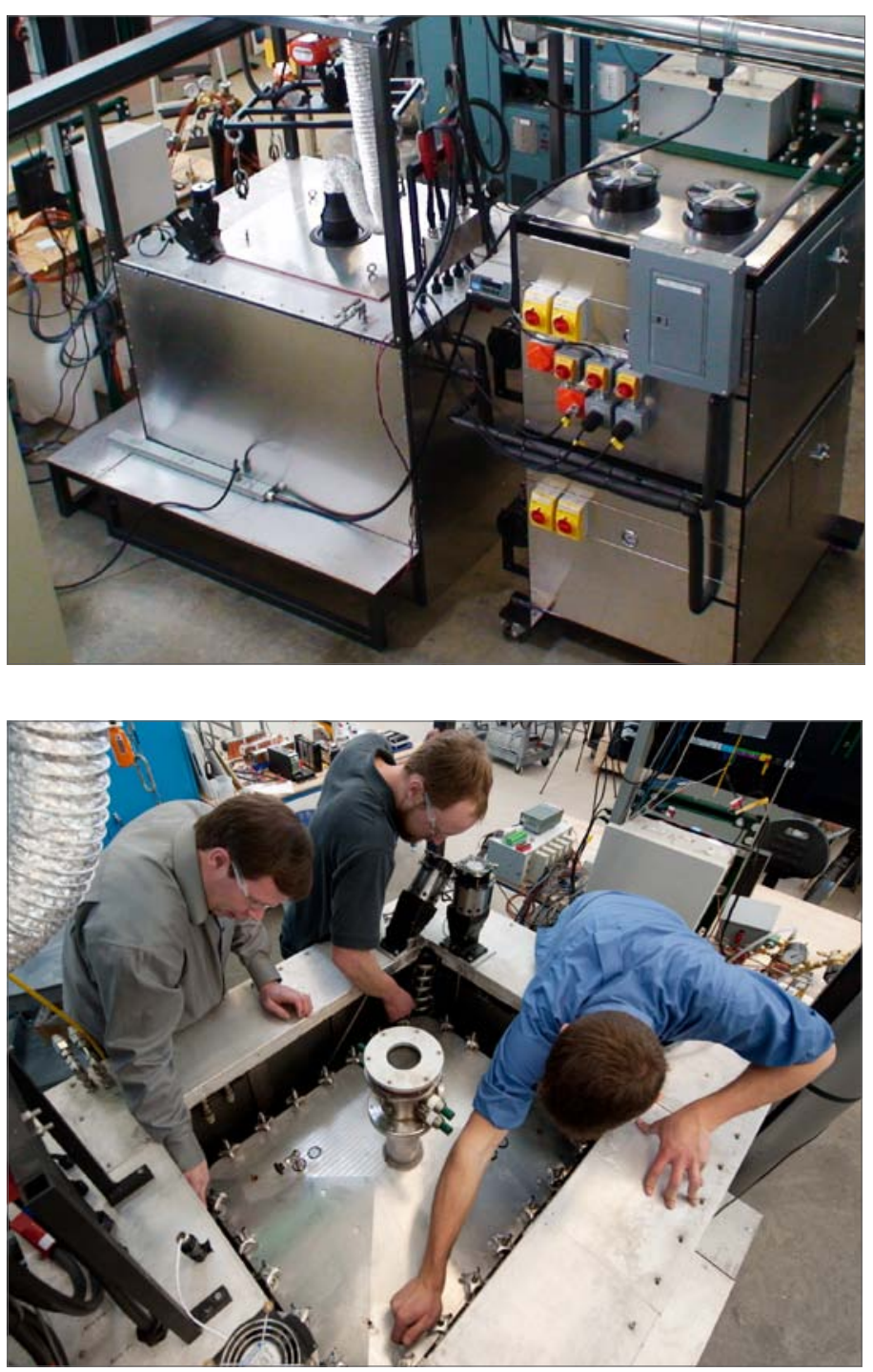

\section{NREL Contacts}

Matthew Keyser, Senior Engineer Battery Thermal Test Facility, Manager Matthew.Keyser@nrel.gov 303-275-3876
Ahmad Pesaran, Principal Engineer Energy Storage Team Lead Ahmad.Pesaran@nrel.gov 303-275-4441
Barbara Goodman, Director

Center for Transportation Technologies and Systems

Barbara.Goodman@nrel.gov 303-275-4455

NREL Energy Storage Website: www.nrel.gov/vehiclesandfuels/energystorage

NREL/BR-5400-50558 • June 2011

Printed with a renewable-source ink on paper containing at least $50 \%$ wastepaper, including $10 \%$ post consumer waste. 